9. Popular academy pictures. The Times 4 May 1915.

10. RLHLH/A/5/54, House committee minutes. 21 June 1915.

11. The McManus, Dundee. Inventory No. 2-1916.

12. Hone J. The Life of Henry Tonks. London: William Heinemann Ltd, 1939

13. Clark-Kennedy AE. The London: A Study in the Voluntary Hospital System. 2 Vol London: Pitman Medical Publishing, 1963.

14. RLHLH/PP/PAU/28, Letter to Mrs Margaret Jessie Paul from Matron, 24 August 1914.

15. RLHLH/MC/A/24, London Hospital Gazette, 'Quarterly Report'. December 1914.

16. RLHLH/MC/A/24, London Hospital Gazette, 'Unofficial Report to Quarterly Court by Mr. E.W. Morris'. September 1914.

17. Arrival of wounded in London. The Times 31 August 1914.

18. RLHLH/A/5/54, House Committee Minutes, Matron's Annual Letter. June 1915.
19. RLHLH/M/1/43, London Hospital Surgeons' In Patient Register; RLHLH/M/1/82 London Hospital Medical Register.

20. Atenstaedt RL. Trench foot: the medical response in the First World War 1914-18. Wilderness Environ Med 2006;17:282-9.

21. Maguina C, Guerra H, Ventosilla P. Bartonellosis. Clin Dermat 2009;27:271-80.

22. RLHLH/N/1/5, Register of Probationer Nurses.

23. RLHLH/N/4/1, Register of Sisters and Nurses.

24. Lückes ECE. General Nursing. 9th edn. London: Kegan Paul, Trench, Trübner \& Co. 1914.

25. How The London rose to an Emergency. The Times 3 September 1914.

26. Anon. The rôle of tobacco in the war. Lancet 1914;184:857-8.

27. RLHLH/N/6/23, Ward Book. 30 January 1915.

28. RLHLH/N/6/23, Ward Book. 6 February 1915.

\title{
Poem
}

\section{Hot Flash}

Finally, just as it is becoming an environmentally unfriendly lighting option,

Beginning tamoxifen gives me empathy for the incandescent light bulb.

The tiny inner filament heats up, reddening.

The hot glow spreads, heating up the bulb

until the surface glows with heat and shines with light.

Upon extinguishing, the heat fades from the filament,

gradually dissipating from the bulb.

I feel a tiny locus of heat deep inside my body.

Oh no, again?

Before I can answer,

warmth fills my whole body

until my skin glows with heat, glistens with sweat.

Gradually, it dissipates. I have no control.

Unlike for the light bulb, for me there is no switch.

When will I glow again?

\section{Colleen T Fogarty}

Correspondence to Colleen T Fogarty, Assistant Professor, Department of Family Medicine, 1381 South Avenue, Rochester, NY 14620, USA; colleen fogarty@urmc.rochester.edu

Competing interests None.

Provenance and peer review Not commissioned; not externally peer reviewed.

Published Online First 6 April 2011

J Med Ethics; Medical Humanities 2011;37:26. doi:10.1136/jmh.2011.007724 